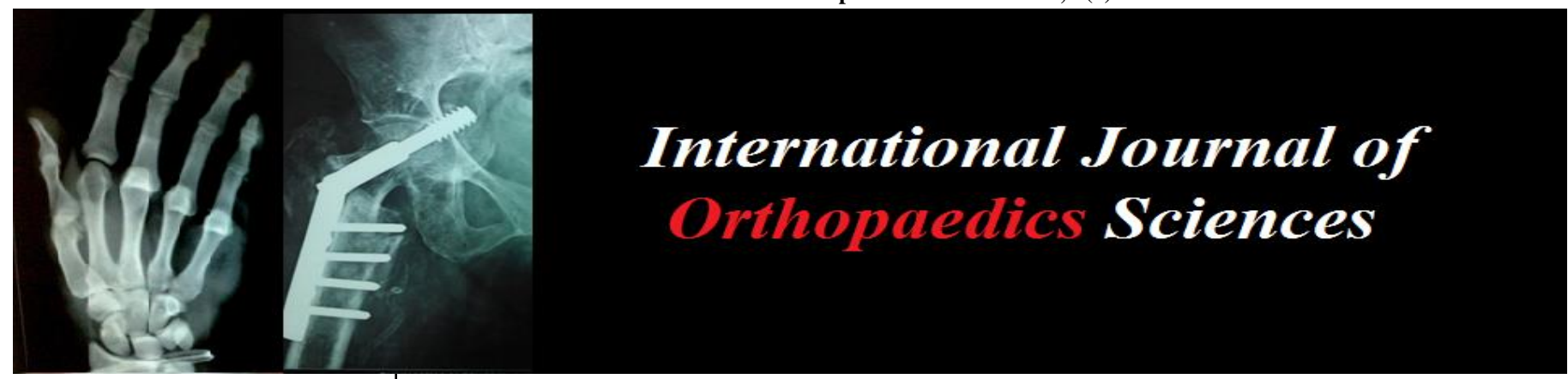

ISSN: $2395-1958$

IJOS 2018; 4(2): 584-589

(C) 2018 IJOS

www.orthopaper.com

Received: 14-02-2018

Accepted: 17-03-2018

Dr. Shaik Ajaz

Department of Orthopaedics, Associate Professor, Deccan

College of Medical Sciences,

Telangana, Hyderabad, India

Dr. Chinnala Srujan Kuma Department of Orthopaedics, Junior Resident, Malla Reddy Institute of Medical Sciences,

Telangana, Hyderabad, India

Correspondence

Dr. Shaik Ajaz

Department of Orthopaedics,

Associate Professor, Deccan

College of Medical Sciences,

Telangana, Hyderabad, India

\section{Study of the principles of ponseti technique in the management of idiopathic congenital talipes equinovarus}

\author{
Dr. Shaik Ajaz and Dr. Chinnala Srujan Kumar
}

DOI: https://doi.org/10.22271/ortho.2018.v4.i2i.87

\section{Abstract}

Clubfoot is one of the commonest congenital conditions seen in orthopaedic practice. Though congenital talipes equinovarus (CTEV) exists from time immemorial, its etiology is unknown, pathology is complex and management is full of controversies. Till today, the orthopaedic surgeons are constantly confronted with new techniques and operations in its management. It requires judicious selection of cases and use of appropriate method of treatment. We have passed through the phase of forcible manipulation of clubfoot to microsurgical operative techniques and correction by external fixator. In spite of careful research it remains a source of dissatisfaction even to most enthusiastic surgeons. This study consists of treatment of idiopathic clubfoot conservatively using Ponseti technique.

Keywords: idiopathic congenital talipes equino varus, ponseti technique, pirani score

\section{Introduction}

In the evolutionary process, humans attained the bipedal posture. This being a unique feature in animal kingdom, is mainly attributed to the evolutionary changes of the foot. If such a foot is deformed, the life style man adopted and supposed to live is greatly compromised. Clubfoot is one of the commonest congenital conditions seen in orthopaedic practice. Though congenital talipes equinovarus (CTEV) exists from time immemorial, its etiology is unknown, pathology is complex and management is full of controversies. Hippocrates 400 B.C described about club foot in his literature. Till today, the orthopaedic surgeons are constantly confronted with new techniques and operations in its management. It requires judicious selection of cases and use of appropriate method of treatment. We have passed through the phase of forcible manipulation of clubfoot to microsurgical operative techniques and correction by external fixator. In spite of careful research it remains a source of dissatisfaction even to most enthusiastic surgeons. This study consists of treatment of idiopathic clubfoot conservatively using Ponseti technique.

\section{Materials and Methods}

This study was conducted in the department of Orthopaedics, Princess Esra Hospital, Deccan College of Medical Sciences, during the period of June 2008 to September 2010. The clinical material comprised of all children with idiopathic C.T.E.V of age from birth up to 7 months of age who attended the Orthopaedic out patient service of the department during the above said period. The entire treatment was given in the outpatient service only. Those children requiring percutaneous tenotomy and posteromedial soft tissue release were admitted prior to surgery. We excluded those patients who already had some other modality of treatment from our study. Complete history including birth history, family history and developmental mile stones taken. All patients were clinically examined in detail with special regard to deformities of foot, other congenital anomalies like Meningocele, Arthrogryposis, Umbilical Hernia, Congenital Dislocation of Hip, Genito-urinary anomalies, etc. The deformity was classified according to system of Dimeglio et al. as Grade I. Grade II. Grade III and Grade IV. According to Pirani clinical scoring, hind foot and mid foot scores of each fool calculated and added to get total Pirani score. 


\section{Pirani scoring system}

Dr. Pirani has developed a reliable and valid method of clinically assessing the amount of deformity present in an unoperated congenital clubfoot less than 2 years of age. It is useful because it is reliable and with valid measurements.

Documenting the amount of deformity during the course of the treatment allows the treating practitioner (especially if inexperienced) to know when tenotomy is indicated and to reassure parents regarding progress. It allows meaningful comparison of results, extraction of sub-groups etc.

\section{Use of Pirani score}

Scoring: Every clubfoot under Ponseti management is "scored" each week for hind foot score, mid foot score and total score.

Plotting: Plotting scores on graph shows where the foot is on the roadmap treatment visually and easily reassuring parents of satisfactory progress.

Tenotomy: Tenotomy is indicated to correct Hind foot contracture if hindfoot score is greater than 1 when mid foot contracture is corrected i.e the lateral head of talus is covered and mid foot score is equal to or less than 1 .

\section{Treatment regimen}

All patients of less than 7 months were treated by Ponseti technique as soon as possible. Treatment consists of gentle manipulation of the foot and serial application of long leg plaster cast without the use of anesthesia as described by Ponseti. In all patients, cavus was first corrected by supinating the forefoot and dorsiflexing the first metatarsal. To correct the varus and adduction the foot in supination was abducted while counter pressure was applied with the thumb against the head of talus. Casts were changed weekly or once in two weeks after proper manipulation of foot until good correction is obtained. If residual deformity is observed after the adduction of foot and varus deformity of the heel has been corrected, a simple Percutaneous tenotomy of the Achilles tendon was performed under local or short general anesthesia After tenotomy a cast was applied and left in place for three weeks to allow for heeling of tendon. Dennis-Browne splint was used to prevent relapse of the deformity the brace was fitted on the same day as the last POP cast was removed we used well fitted, open toad, high-top. Straight-last shoes attached to Dennis-Browne bar of length equal to the distance between the child's shoulders. The corrected foot was maintained in 70 degrees of external rotation with ankle in dorsiflexion. The normal foot in a unilateral deformity was placed in 45 degrees of external rotation. The brace was worn for $23 \mathrm{hrs}$ a day for first three months and then at night for $12 \mathrm{hrs}$ for next $3 \mathrm{yrs}$. The parents were instructed to perform range of motion exercises for the ankle and foot when it was out of the brace. Two exercises were taught to the parents. In the first exercise the infant was made to squat on level ground while being supported by the parent. This brought the ankle in dorsiflexion and prevents equines. Deformity. In the second exercise the parent stabilized the leg w.th one hand while using the ether hand to grasp the foot The lateral border of the foot was then approximated towards the shin of the leg These exercises were repeated 20 times at each sitting The exercises were performed twice a day for the first 3 months and five times daily for next 3 yrs. The patients were followed up on a weekly basis during the initial stages of treatment. After brace was applied, the patient was seen on a monthly basis for three months and then once every three months till the patient was $3 y r s$ of age. The patient was also followed up every 6 months to 1year till skeletal maturity is achieved. During each follow up we analyzed the functional status of foot and checked for any recurrences and advised parents about the exercises and strict bracing protocol.

\section{Results}

Each foot was evaluated cosmetically, functionally and rated according to the following criteria:

\section{A. Excellent}

1. Complete correction of all components of the deformity.

2. Plantigrade cosmetically acceptable foot.

3. Pliable subtalar motion.

4. Dorsiflexion equal to the normal side or above the right angle in bilateral deformities.

\section{B. Good}

1 Complete correction of all components of deformity.

2. Fully plantigrade and mobile foot with minor degree of persistent metatarsus adduction.

\section{Fair}

1. Plantigrade and functionally acceptable foot.

2. Cosmetically less acceptable.

3. Some loss of initial correction, which is correctable by re-manipulation and Casting.

\section{Poor}

1. Loss of correction and recurrence of the deformity which requires soft tissue release.

of the 32 patients that were followed up there were 12 $(37.5 \%)$ females and $20(62.5 \%)$ males.

With $26(81.25 \%)$ cases having bilateral involvement, 4 (12.5\%) Right sided and $2(6.25 \%)$ Left sided involvement. Most of them were between the age groups of 0-4 months (84.375)

\section{Clinical grade of foot}

\begin{tabular}{|c|c|c|}
\hline Dimeglio grade & Number of feet & Percentage \\
\hline I & 0 & 0 \\
\hline II & 12 & 20.69 \\
\hline III & 26 & 44.83 \\
\hline IV & 20 & 34.48 \\
\hline
\end{tabular}

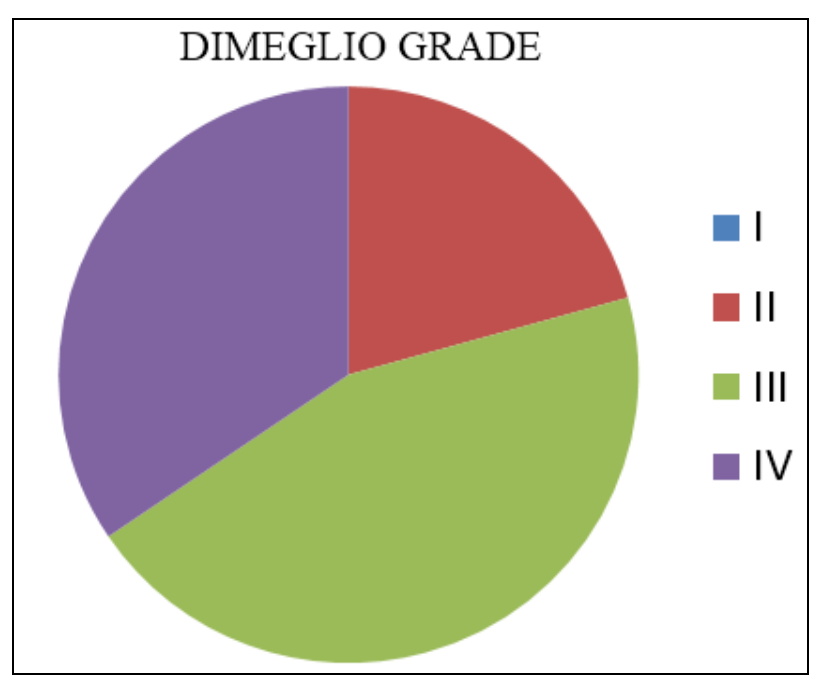


Initial Total Pirani Score

\begin{tabular}{|c|c|c|}
\hline Initial total pirani score & Number of feet & Percentage \\
\hline 4 & 10 & 17.24 \\
\hline 4.5 & 3 & 5.17 \\
\hline 5 & 24 & 41.37 \\
\hline 5.5 & 6 & 10.34 \\
\hline 6 & 15 & 25.86 \\
\hline
\end{tabular}

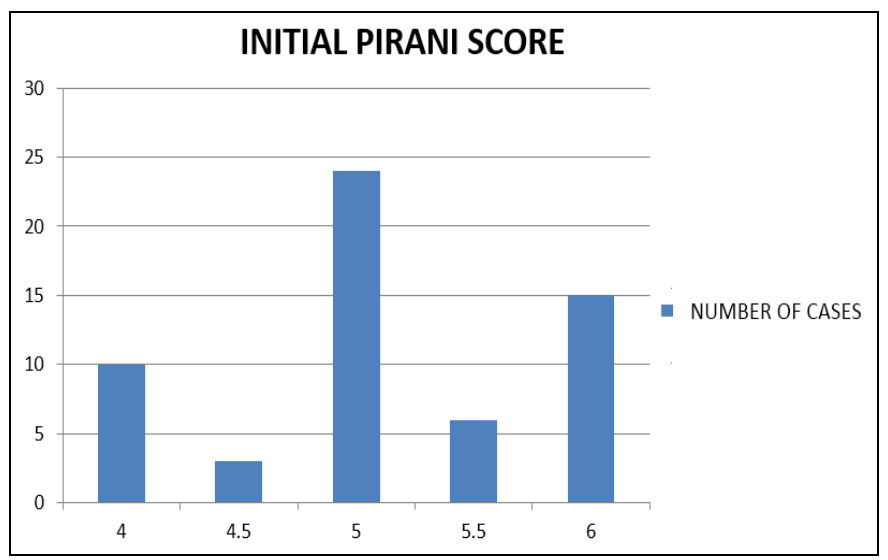

\section{Associated Anomalies}

\begin{tabular}{|c|c|c|}
\hline Associated anomalies & Number of cases & Percentage \\
\hline Present & 5 & 15.62 \\
\hline Absent & 27 & 84.38 \\
\hline
\end{tabular}

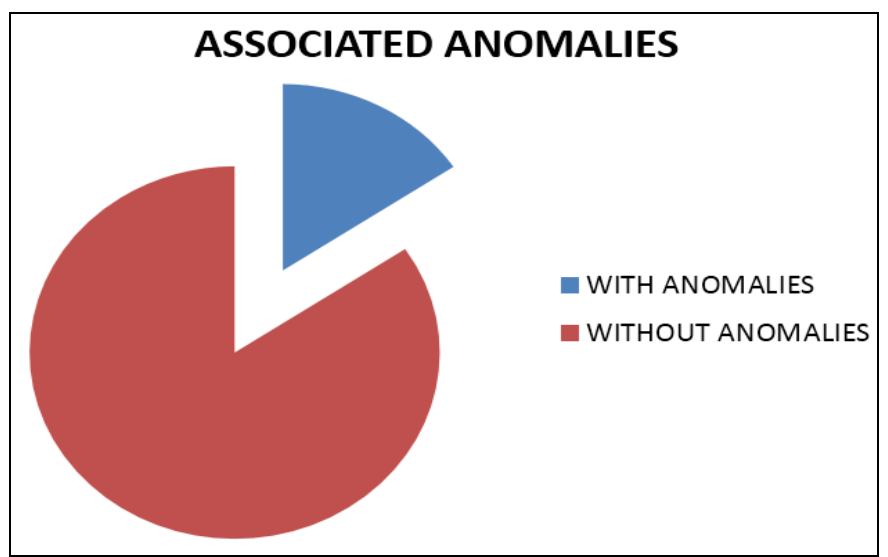

\section{Number of Casts Required}

\begin{tabular}{|c|c|c|}
\hline Number of casts & Number of cases & Percentage \\
\hline 5 & 13 & 40.62 \\
\hline 6 & 17 & 53.12 \\
\hline 7 & 2 & 6.26 \\
\hline
\end{tabular}

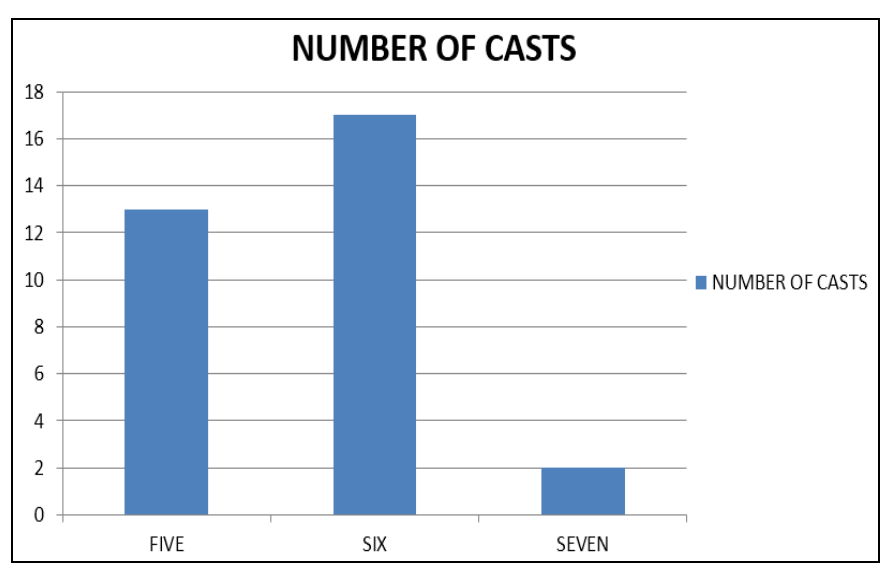

Percutaneous Tenotomy

\begin{tabular}{|c|c|c|}
\hline Percutaneous tenotomy & Number of feet & Percentage \\
\hline Required & 30 & 51.72 \\
\hline Not required/PMSTR & 28 & 48.28 \\
\hline
\end{tabular}

\section{PERCUTANEOUS TENOTOMY}

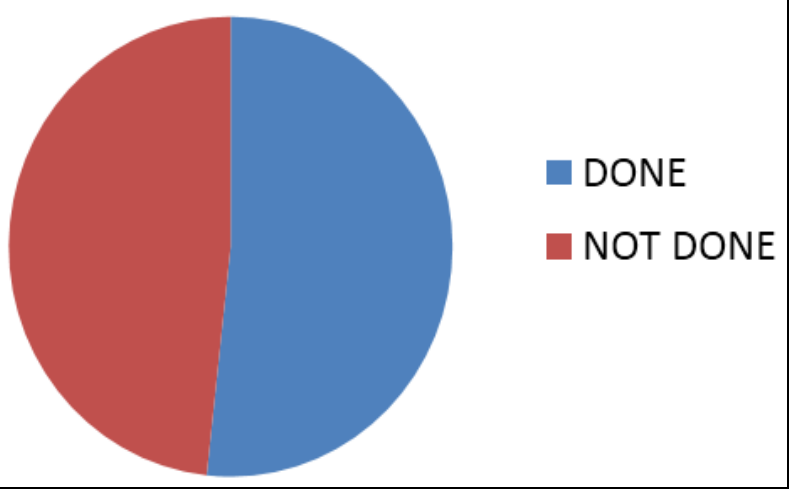

\section{Results}

\begin{tabular}{|c|c|c|}
\hline Result & Number of feet & Percentage \\
\hline Excellent & 35 & 60.34 \\
\hline Good & 15 & 25.86 \\
\hline Fair & 0 & 0.00 \\
\hline poor & 8 & 13.79 \\
\hline
\end{tabular}

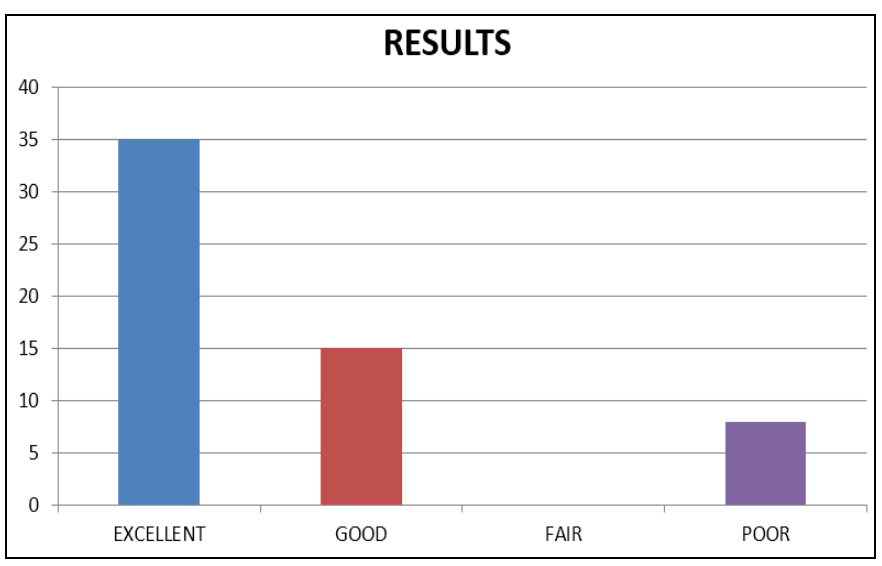

\section{Discussion}

Congenital talipes equinovarus is the commonest of all deformities forming, about $80 \%$ of the cases. Its incidence is about 1 in every 1000 live births being commoner in India, when compared to western countries. The condition is bilateral in about $66 \%$ of cases being commoner in males'. The commonest type is idiopathic. This is one condition where early, effective and continued treatment gives good results and without treatment the deformity increases and the foot becomes permanently deformed with callosities and ulceration over the dorsolateral aspect of foot. The human cost of neglected clubfoot is enormous, particularly for women and children afflicted females are less likely to marry and more likely to suffer abuse Worldwide neglected clubfoot a considered to be the most serious cause of physical disability from musculoskeletal birth defects. In 1948, Ponseti proposed reducing the deformity with successive casts although treatment with cast is a very old method. Ponseti method is based on strict rules established from anatomic evidence the goal is not to correct the apparent deformation, but on the contrary, to impose a Simultaneous supination and abduction of the foot once the calcaneopedal block has been 
derotated. Percutaneous tenotomy of Achilles tendon is performed. Extensive open surgery like posteromedial release is commonly associated with long term stiffness and weakness which is avoided by the Ponseti's technique Comparative studies have shown advantages of Ponseti's technique of management over traditional methods of casting Correction of heal varus and the increased decimation angle of neck of the talus are better in a club foot treated with Ponseti method of management as compared to traditional casting methods Three dimensional CT reconstruction of whole foot also showed that cavus supination and adduction are corrected much better with Ponseti method In correcting the deformity Ponseti mainly stressed on keeping the talar head as the fulcrum instead of calcaneocuboid joint as done in Kite s method. Ponseti technique has been reported with $92 \%$ to $98 \%$ successful results for the idiopathic clubfoot. We have successfully corrected $50(86.20 \%)$ of 58 clubfoot deformities using Ponseti method. 1 bilateral CTEV case developed recurrence of the deformity were due to non-compliance with the use of brace. This reason has been widely reported to be the main factor causing failure of technique. The remaining 4 cases (6 foot) were not corrected by Ponseti's technique, required posteromedial soft tissue release. Serious bleeding complications following percutaneous tendo Achilles tenotomy is not seen in any our tenotomy or posteromedial soft tissue release surgery. Mandatory bleeding time, clotting time protocols before surgery also helped us in preventing this complication. In present series we have treated 32 patients with 58 idiopathic clubfoot deformities using Ponseti method of management The average age of the patterns was 2 months (ranging from one week to 7 months) Among the 32 infants, 6 had unilateral and 26 had bilateral involvement. Among the 32 infants 20 were males and 12 were females none of these have received any surgical treatment before referral. Most of the patients had Grade III and Grade IV deformity the average number of casts required were SIX applied over a period of 10 weeks. Among the 58 foot, only 20 required percutaneous tenotomy, Totally 50 foot $(86.2 \%)$ were treated successfully using Ponseti's technique. In 2 foot (1 B/L CTEV case), deformity recurred because of non-compliance of brace. It is corrected by reapplying the casts from the first step and finally it required posteromedial soft tissue release. The remaining 6 foot could not be corrected with Ponseti's technique alone and hence corrected with posteromedial soft tissue release.

\section{Conclusions}

Congenital talipes equinovarus (CTEV) is commonest of all foot deformities being commoner in male children and bilateral in $81.25 \%$ of cases in our study. Idiopathic type being the commonest form. The Ponseti method is a safe and effective treatment for congenital idiopathic clubfoot in children up to seven months of age This technique can also be used in cases of relapses This method reduces the need for extensive corrective surgery which is associated with complications although the foot looks better after surgery, it is stiff weak and often painful after adolescence, pain increases and often becomes crippling. Ponseti method is particularly suited for developing countries where there are few orthopaedic surgeons. The technique is easy to learn by allied health professionals, such as therapists and orthopaedic assistants the treatment is economical and easy on the babies if well implemented, it will greatly decrease the number of clubfoot cripples. We conclude that Ponseti method is an easy, effective efficient and economical mode of management of congenital idiopathic clubfoot.

\section{Case 1}

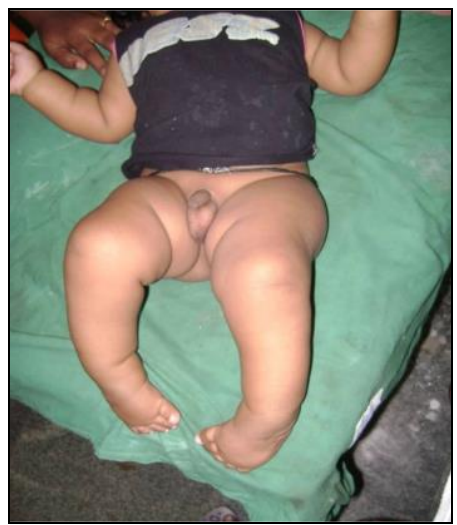

Pre Correction

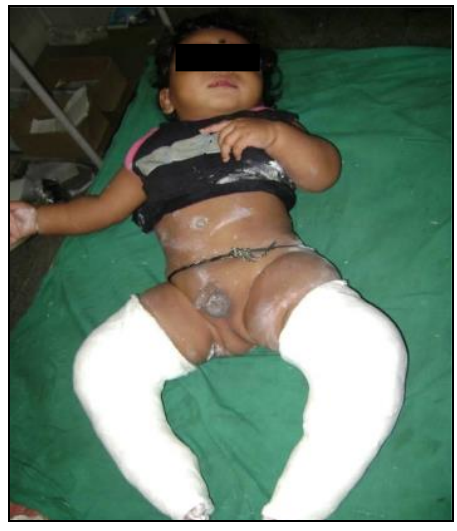

$3^{\text {rd }}$ Cast
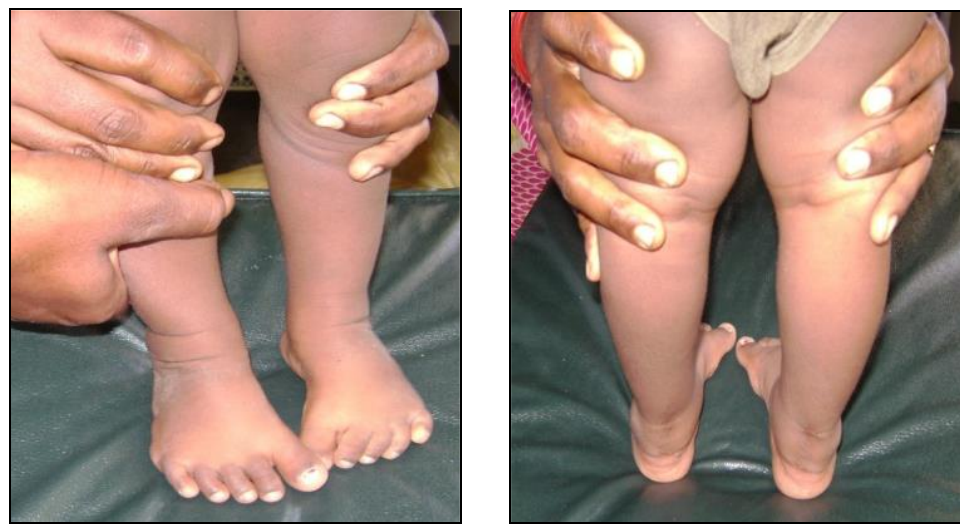

6 Months Follow Up After Tenotomy 


\section{Case 2}

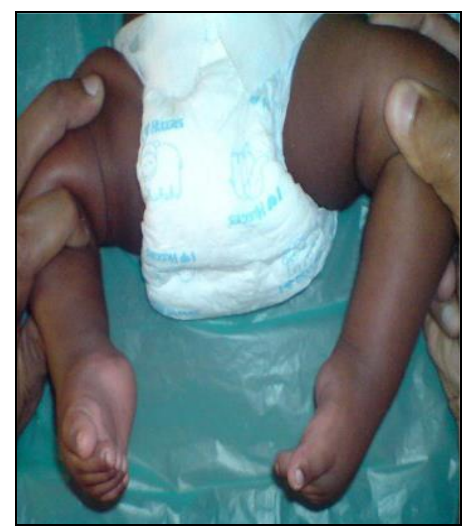

Pre Correction

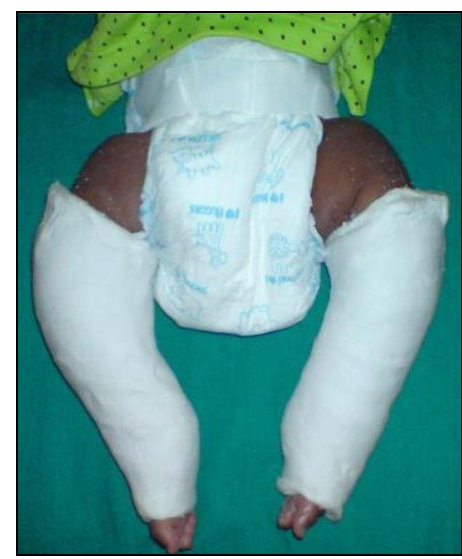

1st Cast

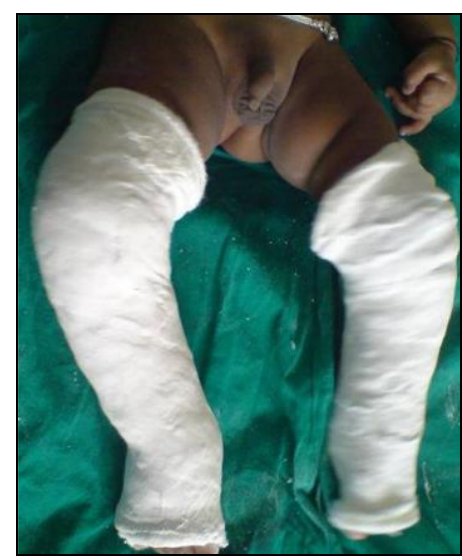

Final Cast

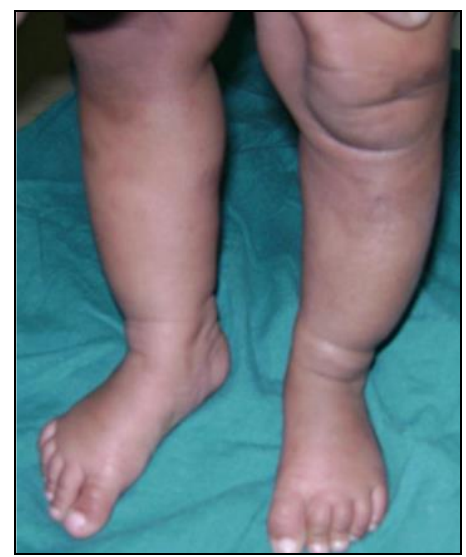

3 Month Follow Up

\section{References}

1. Netters concise atlas of orthopaedic anatomy, Jon. C. Thomson, M. D 1st edition.

2. Netters orthopaedics by WALTER. B. GREENE, 1st edition. Greys Anatomy for Student.

3. Congenital club foot, fundamentals of treatment by Dr. IV. PONSETI. Oxford university press, 1996

4. Ponseti technique posters by Lynn. Staheli; approved by Dr. I. V. PONSETI. www.global-help.org

5. Idiopathic Congenital Talipes Equinovarus David $P$. Roye, Jr, MD, and Benjamin D. Roye, MD, MPH Journal of American academy of orthopaedic surgery. 2002; 10:239-248.

6. Nonsurgical Management of Idiopathic Clubfoot Kenneth J. Noonan, MD, and B. Stephens Richards, M. Journal of American academy of orthopaedic surgery. 2003; 11:39240230.

7. Morcuende JA, Dolan L, Dietz F, Ponseti IV Radical reduction in the rate of extensive corrective surgery for clubfoot using the Ponseti method. Pediatrics. 2004; 113:376-380.

8. The Journal of Bone and Joint Surgery (American). 2007; 89:1177-1183.

doi:10.2106/JBJS.F.00438 (C) 2007 The Journal of Bone and Joint Surgery, Inc.

9. A Standardized Method for the Radiographic Evaluation of Clubfeet GEORGEW. SIMONSM, DMS. (ORTHO)

10. CAMPBELL"S Operative Orthopaedics; Eleventh edition, 2, 1079-1100.

11. Club foot: Ponseti Management; Editor-Lynn Staheli, Global Help publication, 2003.

12. Keret D, Ezra E, Lokiec F. Efficacy of prenatal ultrasonography in confirmed club foot. J Bone Joint Surg Br. 2002; 84:1015.

13. Victoria-Diaz A, Victoria-Diaz J. Pathogenesis of idiopathic clubfoot. Clincal Orthop Relat Res, 1984, 14.

14. Kawashima T, Uhthoff HK. Development of the foot in prenatal life in relation to idiopathic club foot. J Pediatr Orthop. 1990; 10:232.

15. Ponseti IV, Smoiey EN. Congenital club foot: The Results of Treatment. Journal of Bone \& Jo. nl Surgery. 1963; 45A(2):2261-2270.

16. Ponseti IV. Becker JR Congenital Metatarsus Adductus: The Results of Treatment' Journal of Bone \& Joint Surgery 43AI4), 1966, 702-711.

17. Irani, RN, Sherman MS. The pathological anatomy of club foot. Journal of Bone and Joint Surgery. 1963; 45A:45.

18. Campos J. Ponseti IV 'Observations on Pathogenesis and Treatment of Congenital Clubfoot" Clinical Orthopaedics and Related Research. 1972; 84:50-60.

19. Ionasescu V, Maynard JA, Ponseti IV. Zellweger H. The Role of Collagen in the Pathogenesis of Idiopathic Clubfoot Biochemical and Electron Microscopic Correlations' Helvetica Paediatrica Acta. 1974; 29(4):305-314.

20. Ippolito E, Ponseti IV. Congenital Clubfoot in the Human Fetus: A Histological Study Journal of Bone A Joint Surgery. 1980; 62A(1):8-22.

21. Laaveg SJ, Ponseti IV. Long-term Results of Treatment of Congenital Clubfoot. Journal of Bone and Joint Surgery. 1980; 62A(1):23-31.

22. Brand RA, Laaveg SJ, Crownmshield RD, Ponseti IV. The Center of Pressure Path in Treated Clubfoot" Clinical Orthopaedics and Related Research. 1981 ; 160:43-47. 
23. Ponseti IV, Ei-Khoury GY, ippolito E, Weinstein SL. A Radiographic Study of Skeletal Deformities in Treated Clubfoot Clinical Orthopaedics and Related Research. 1981; 160:30-42.

24. Ponseti IV. Treatment of Congenital Clubfoot' Journal of Bone \& Joint Surgery. 1992; 74A(3):440-454.

25. Ponseti IV. The Treatment of Congenital Clubfoot (Editorial) Journal of Orthopaedic \& Sports Physical Therapy. 1994; 20(1):1.

26. Ponseti IV. Common Errors in the Treatment of Congenital Clubfoot International orthopaedics. 1997; 21(2):137-141.

27. Ponseti IV. Correction of the Talar Neck Angle in Congenital Clubfoot with Sequential Manipulation and Casting Iowa Orthopaedic Journal, 1998; 18:74-70.

28. Ponseti I. Clubfoot Management' Journal of Peadiatric Ortthopaedics. 2000; 20(6):699-700.

29. Ippolito E, Farsetti P, Catereni R, Tudisco C. Long-term Comparative Results in Patients with Congenital Clubfoot Treated with Two Different Protocols Journal of Bone \& Joint Surgery. 2003; 85A(7):1286-1294. 